advocacy as a way to transform life after suicide.

The book contains quotes from Oregon Senator Gordon Smith and his wife Sharon who lost their son Garrett to suicide. As part of the US National Strategy for Suicide Prevention, the Smiths led the initiative to develop suicide prevention programs at colleges and universities. The Garrett Lee Smith Memorial Act was signed into law in October 2004.

Canada could benefit from similar survivor advocacy in order to continue the momentum necessary to creating a national suicide prevention strategy. Unfortunately, Canada remains one of the few developed nations without a national suicide prevention strategy. The good news is that Canadian survivors are moving from grief to action. The Canadian Association for Suicide Prevention (CASP), a well-integrated organization of health care practitioners and survivors, has developed the CASP Blueprint for a Canadian $\mathrm{Na-}$ tional Suicide Prevention Strategy. In May 2006, the Standing Senate Committee on Social Affairs, Science and Technology's report, Out of the Shadows at Last, called upon the federal government to support the efforts of CASP and other organizations working to develop a national suicide prevention strategy. The contact information for CASP (www.suicideprevention.ca) and other advocacy organizations are given in the resource directory of the book.

Touched by Suicide is moving and well produced. I had only a few minor criticisms. The book is targeted at an American audience and some Canadian resources for survivors, such as the Survivor Listserve (SurvivorAdvocatessubscribe@yahoogroups.com) created by the Canadian Association for Suicide Prevention, are noticeably missing. Initially designed to connect "Survivors in Action," the Listserve membership has evolved to also include health care practitioners interested in suicide prevention.

The book also covers some obscure topics, such as police suicides and murder/suicide. I wish the authors had used the room to provide more information about common psychiatric dis- orders related to suicide such as schizophrenia and borderline personality disorder.

In addition, when the authors are discussing the genetic risk for suicide, they need to make it clearer that research suggests that the risk for suicide seems to be inherited independent of the risk for psychiatric disorders. For example, you can find families with a heavy familial loading for bipolar disorder but no increased risk for suicide.

Physicians must be prepared to cope with the aftermath of a suicide among their patients and to offer guidance to the family surviving and needing to heal from this loss. This new book by Myers and Fine will be an invaluable resource to assist physicians in one of their most difficult but impactful roles: guiding the healing of suicide survivors.

Paul S. Links

Psychiatrist

Arthur Sommer Rotenburg Chair

in Suicide Studies

University of Toronto

Toronto, Ont.

\title{
Poem
}

\section{All the ward's a stage: a surgeon's sonnet}

Too soon the curtain of this stage will rise Well trained am I and in this role well versed

In readiness again I don my guise

Yet fear and trembling parch my throat with thirst

My face assumes a self assured masque

The company does not suspect I feign

I force myself to focus on the task

I must find strength to play my part again.

In spite of every effort tried last night

That blackest of all curtains dark did fall

Today we must continue in the fight

Returning to the spotlights of the hall.

One last attempt to calm my trembling heart

Then off I go to play my fateful part.

As physicians we try to distance ourselves emotionally from our work, but find there are always cases that affect us. Sometimes things do indeed go very wrong, despite our best preparations and intentions. No matter how humbling the event, we often have no choice but to return and perform the same procedure.

Wai Pui Ng
Deurosurgeon
Lepartment of Clinical Neurological
Sciences
London Health Sciences Centre

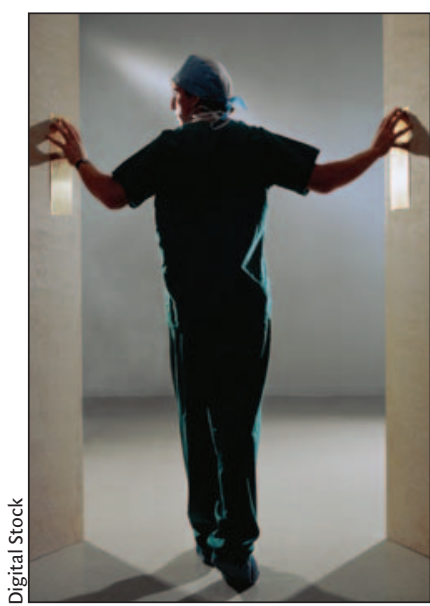

